\title{
Are South African equity investors rewarded for taking on more risk?
}

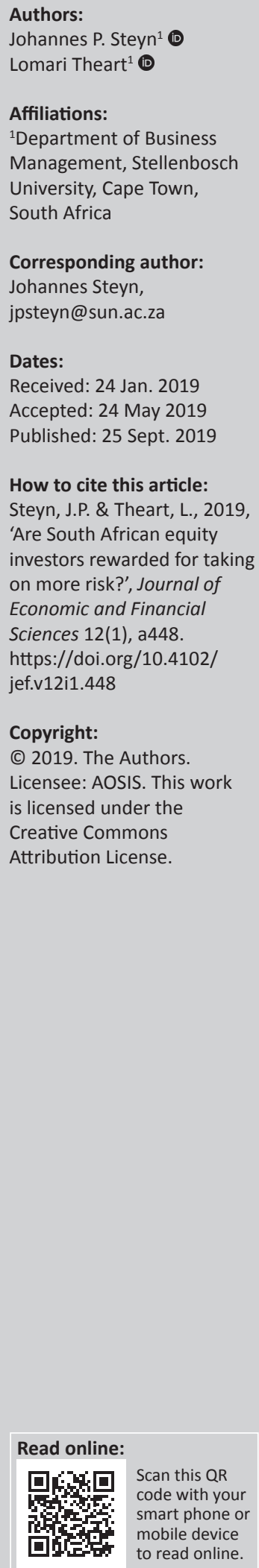

Orientation: It is rational for investors to expect additional compensation for an increased risk exposure. This positive risk-return relationship is in line with traditional financial theory; however, this relationship does not always hold in empirical research.

Research purpose: The aim of this article was to investigate the prevalence of the low-risk anomaly in the South African equity market.

Motivation for the study: If there is evidence of a low-risk anomaly, where low-risk shares outperform high-risk shares, then the additional return expectation of investors may be misplaced.

Research design/approach and method: A unique sampling procedure and an extended time frame were employed in a quintile portfolio analysis methodology.

Main findings: The article presents evidence that South African listed shares with low historical volatility earned higher risk-adjusted returns over the period July 2004 to September 2018. Low-volatility shares delivered a Sharpe ratio of 1.10 compared to 0.65 produced by the Financial Times Stock Exchange / Johannesburg Stock Exchange Shareholder Weighted Index over the same period.

Practical/managerial implications: The assumption that return in an investment portfolio could be enhanced by taking on more risk could be wrong. It seems that fund managers could potentially enhance returns and decrease risk in their portfolios by focussing on shares with low historical volatility.

Contribution/value-add: The negative relationship observed between volatility and return is inconsistent with theoretical expectations. Therefore, the results of this article suggest that investors are not rewarded for assuming higher levels of risk.

Keywords: low risk; risk-adjusted return; volatility; beta; standard deviation; anomaly.

\section{Introduction}

Investors should expect higher returns for taking on greater levels of risk. The relationship between risk and return became a fundamental concept in finance during the early 1950s. Before that, the investment decision (and the evaluation of portfolio performance) was simply based on the rate of return. In 1952, Harry Markowitz proposed an investment theory, Modern Portfolio Theory (MPT), stating that investors should construct efficient portfolios, depending on their desired risk-return combination. An efficient portfolio is one that simultaneously maximises expected return and minimises the variance or volatility (Markowitz 1952). In other words, investors should be attracted to portfolios that minimise risk for an acceptable level of expected return, or prefer portfolios that maximise expected return for an acceptable level of risk.

Capital market theory (CMT), generally credited to Sharpe (1964), extended the MPT introduced by Markowitz by developing a model for pricing all risky assets. This was carried out by introducing the concept of a risk-free asset and designating a market portfolio containing all risky assets. The capital market line (CML) offered a way to relate the return investors can expect to investment risk (as measured by total volatility). Because investors cannot expect to be compensated for bearing risk that they could have diversified away, the CML implicitly assumes investors all hold the same fully diversified portfolio, the market portfolio. An extended model, the capital asset pricing model (CAPM), was then proposed. The CAPM allows investors to determine the required rate of return for any risky asset or diversified portfolio by relating it to the return of the market portfolio. The CAPM thus redefined the relevant measure of risk from total volatility to the risk relative to the market portfolio. The CAPM, therefore, relates expected return of an asset to its systematic risk, or beta (Sharpe 1964). 
The implied trade-off between risk and return is that higher levels of risk must be compensated for with higher expected returns. In this regard, MPT and CMT derived a positive risk-return relationship for investment securities, suggesting that risk in a portfolio should be priced. However, global empirical evidence suggests that low ex-ante volatility shares outperform high-volatility shares (Blitz \& Van Vliet 2007; Ludvigson \& Ng 2005). Blitz and Van Vliet (2007) provided evidence of a negative risk-return relationship in European and Japanese equity markets. Six years later, Blitz, Pang and Van Vliet (2013) conducted the same study for emerging equity markets and found a flat, or in some markets even negative, risk-return relation. To the extent that volatility is often used as proxy for risk, the important implication is that this effect is in contradiction to conventional financial theory where risk is positively related to expected return. In other words, investors should want to pay less for shares with higher levels of observed variance, and they should be willing to pay more for shares with lower observed variance. If the outcome of an investment is uncertain, an investor should demand compensation in the form of a risk premium. However, if there is evidence of a low-risk anomaly, where low-risk shares actually outperform high-risk shares, then this seemingly rational expectation of investors is misplaced. Only when investors understand the real nature of the relationship between risk and return would they be able to avoid the potential pitfall of adding extra risk with the expectation of additional return.

This study aims to build on the existing literature by providing supplementary empirical evidence of a low-risk anomaly in the South African equity market. This is achieved by following a unique sampling procedure, and an extended and updated time frame.

In this study, firstly, an overview of the literature is provided, which is followed by an outline of the research objectives addressed here. The methodology of the study is presented next, followed by the results. Finally, a reconciliation of the research objectives is given, culminating with a discussion, the conclusions and managerial implications.

\section{Literature review}

Modern Portfolio Theory, introduced by Markowitz (1952), is one of the most important and influential economic theories in finance and investment. Employing expected returns, variances and correlation between assets, it provides a framework for quantifying and understanding portfolio risk and return. Modern Portfolio Theory stresses the importance of risk reduction by means of diversification and concludes that higher returns can only be accomplished by the adoption of higher levels of risk.

Capital market theory introduced by Sharpe (1964), simultaneously simplifies Markowitz's MPT, makes it more practical and introduces the idea of systematic versus nonsystematic risk. Capital market theory first introduces an efficiently diversified market portfolio and then links all other assets to this market portfolio by means of the CAPM. This work was later also attributed to Lintner (1965), Mossin (1966) and Treynor (1961) for his unpublished manuscripts: Market Value, Time and Risk (1961) and Toward a theory of Market Value of Risky Assets (1962).

The CAPM states that total risk as measured by the variance of excess portfolio returns $\left(\sigma_{p}^{2}\right)$ can be explained by the uncertainty of the market (the variance of the market excess return $\left(\sigma_{M}^{2}\right)$ and the sensitivity of the portfolio to the market), as well as the variance of the firm specific return $\left(\sigma_{p, \varepsilon}^{2}\right)$ (which is independent from the market). Thus, total risk has two components, namely systematic (market) risk and nonsystematic (firm specific) risk. In line with MPT, which acknowledges the risk reduction benefits of diversification, the CAPM further states that non-systematic risk should be reduced to arbitrarily low levels by means of diversification. An investor can thus only expect to be compensated for bearing systematic risk (risk that cannot easily be diversified away). Therefore, in its simplest form, the CAPM states that the expected portfolio excess return is a direct function of its beta (systematic risk) and the market excess return. The CAPM is given by:

$E\left(r_{p}\right)-r_{f}=\beta_{p}\left(E\left(r_{m}\right)-r_{f}\right)$

[Eqn 1]

where:

$E\left(r_{p}\right)=$ expected return on a portfolio;

$r_{f}=$ risk-free rate;

$\beta_{p}=$ beta or the sensitivity of the portfolio to the market;

$E\left(r_{m}\right)=$ expected return on the market portfolio.

The CAPM therefore suggests that higher levels of return can be expected from taking on higher levels of systematic risk.

In the early 1970s, a few studies noted problems with the implications of the CAPM. Miller and Scholes (1972) and Black, Jensen and Scholes (1972) indicated that the relationship between systematic risk and return is much flatter than suggested by the CAPM. Thus, expected excess returns on high-beta assets are lower and expected excess returns on low-beta assets are higher than suggested by the CAPM. Haugen and Heins (1975) pointed out that the relationship between beta and excess return is not only flat but in fact negative. Expanding their research to total risk (as measured by standard deviation), they yield the same conclusion.

Renewed interest in this field is evident in the early 2000s. Goyal and Santa-Clara (2003) found a significant positive relationship between the average stock variance and market return for NYSE/AMEX/Nasdaq shares over the period 1963 to 1999 . They attributed this phenomenon largely to non-systematic risk and not the beta. Focussing on nonsystematic risk had support in academic research at this point with researchers such as Levy (1978), Merton (1987) and Campbell et al. (2001) all extending the CAPM for investors who hold undiversified portfolios. With an extended sample period (1963-2001), Bali et al. (2005) however found no 
relationship between average stock volatility and value weighted portfolio returns. They attributed the findings of Goyal and Santa-Clara (2003) to small shares and in part to the liquidity premium.

With conflicting results involving the relationship between risk and return, Ang et al. (2006) set out to determine whether market volatility (as proxied by the Chicago Board Options Exchange [CBOE] Volatility Index [VIX]) is a priced risk factor. They concluded that, over the 1986-2000 period, shares with high sensitivity to aggregate volatility had low average returns. Furthermore, they found that shares with high unsystematic risk levels (as measured relative to the Fama and French 1993 three-factor model) have abnormally low average returns. In line with this research, Van Rensburg and Robertson (2003) constructed equally weighted beta quintile portfolios and observed statistical significant outperformance of the low beta portfolio within the South African equity market over the 1990- 2000 period. A similar study performed by Strugnell, Gilbert and Kruger (2011), using more refined measures of beta, similarly concluded statistical significant outperformance of low beta portfolios for the 1994-2007 period.

With a newly termed low-volatility or low-risk anomaly, researchers set out to determine the significance of investing in low-volatility shares. Blitz and Van Vliet (2007), by employing the FTSE World Developed index as sample, set up decile portfolios, and discovered outperformance for low beta portfolios for the 1986-2006 period. Applying the same methodology, but sorting on total volatility, resulted in even higher outperformance for the low-volatility portfolios. Similarly, Blitz et al. (2013) assess the low-volatility effect in emerging markets (including South Africa). In these markets they also found statistically significant outperformance of low-volatility portfolios relative to high-volatility portfolios for the 1989-2010 period.

Baker, Bradley and Wurgler (2011) employed a similar methodology to that of Blitz et al. (2013) on US shares. By compiling quintile portfolios, they detected outperformance of low beta and low-volatility portfolios over the 1968-2008 period. They suggested that the anomaly is partly explained by the fact that the typical institutional investor has a mandate to outperform a fixed benchmark that discourages arbitrage activity. Baker and Haugen (2012) analysed the relationship between volatility and return in 21 developed markets and 12 emerging markets (including South Africa). For a 22-year period (1990-2011), they observed outperformance of low-volatility portfolios across all markets. They ascribed the anomaly primarily to agency issues, specifically the compensation structures and internal stock selection processes at asset management firms that lead institutional investors on average to hold more shares that are volatile.

In an endeavour to provide investable low-volatility portfolios in the South African equity market, studies such as Khuzwayo (2015), Oladele and Bradfield (2016) and
Panulo (2014) evaluated the relative out-of-sample performance of different low-volatility strategies. Khuzwayo (2015) tested the performance of the minimum variance portfolio as proposed by Clarke, De Silva and Thorley (2011) to a similarly constructed high-volatility portfolio. Over the period 2001-2011, Khuzwayo (2015) found statistically significant outperformance (alpha) of the low-volatility portfolio, but discovered that a large proportion of the lowvolatility outperformance can be explained by the relative exposure to the listed property, and financial, industrial and resource sectors.

Panulo (2014) included risk parity portfolios to the menu of low-volatility strategies. Over the 1995-2013 period, this study found significant outperformance of the low-volatility strategies relative to the FTSE/JSE All Share Index (ALSI). Controlling for sector effects, Oladele and Bradfield (2016) employed seven sector-based low-volatility portfolio strategies. They detected outperformance of all seven strategies relative to the ALSI over the 2003-2013 period.

\section{Research objectives}

This study aimed to expand on the available research reporting on the low-risk anomaly in the listed South African equity market. More specifically the relationship between ex-ante risk and subsequent returns was assessed. Risk was measured using two factor metrics, namely standard deviation (a measure of total risk) and beta (a measure of risk relative to the benchmark portfolio).

The primary research objective was to determine whether low-risk portfolios outperform high-risk portfolios over the sample period. The null hypothesis in this regard was that the low-risk quintile portfolio underperformed the high-risk quintile portfolio over the sample period. To determine statistical significance, two hypotheses were employed:

$$
\begin{aligned}
& \mathrm{H}_{01:} \operatorname{Return}_{\text {(Low-risk quintile portfolio) }} \leq \operatorname{Return}_{\text {(High-risk quintile portfolio) }}{ }^{\prime} \\
& \mathrm{H}_{\mathrm{A1}:} \operatorname{Return}_{\text {(Low-risk quintile portfolio) }}>\operatorname{Return}_{\text {(High-risk quintile portfolio) }}
\end{aligned}
$$

If the null hypothesis did not hold, it could be concluded that there is a statistically significant return premium associated with low-risk shares in the market.

The secondary research objective was formulated to provide a more detailed assessment of the low-risk quintile portfolio performance. The null hypothesis in this regard was that the low-risk quintile portfolio outperformed the equally weighted benchmark (EBM) on a risk-adjusted basis as measured by the Sharpe ratio. The Sharpe ratio relates excess returns realised to the standard deviation associated with the portfolio. Therefore, a higher Sharpe ratio would be indicative of superior risk-adjusted returns. To determine statistically significant outperfomance, two hypotheses were employed:

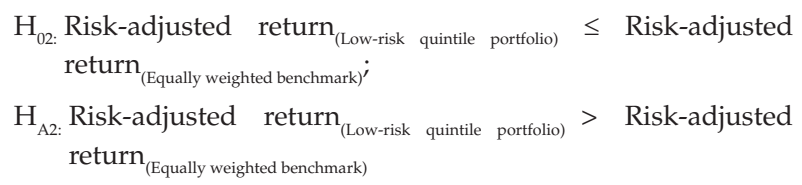


If the null hypothesis did not hold, it could be concluded that there is a statistically significant risk-adjusted return premium associated with holding low-risk shares relative to investing in the EBM portfolio.

\section{Methodology}

The methodology section will address the data collection, data processing and data analysis followed in this article.

\section{Data collection}

The required data for the study were collected from Bloomberg. Weekly price data were used to calculate the factor metrics, whereas adjusted prices were used in order to incorporate the impact of dividends, share splits and share buy backs on portfolio returns. The target population consisted of all shares listed on the JSE over the July 2004September 2018 period. The FTSE/JSE Shareholder Weighted Index (SWIX) constituents were selected as the appropriate sampling frame, given the broad coverage of the index as well as its popularity as an equity fund benchmark.

The SWIX was first introduced in 2003 following concerns about the appropriateness of the ALSI. At that point the ALSI had become increasingly concentrated on a sector basis (specifically resources), and at a share level. The presence of dual-listed shares with low JSE free float contributed to lower investability of the ALSI. The SWIX index methodology adjusted the market capitalisation approach used for the ALSI by making adjustments to the weighting based on the available free float (Johannesburg Stock Exchange 2014). The resulting index had much better diversification and was a better representation of the available opportunity set for South African managers managing portfolios for South African investors.

For this study, a judgemental non-probabilistic sampling technique was employed. To be included in the study a stock had to form part of the top 120 shares in the SWIX index based on its free float adjusted market capitalisation weight for a given month. Thus, this study was limited to larger more liquid shares, screening out small, illiquid and less investable shares. This was done in an attempt to limit the impact of possible size and liquidity effects on the JSE. In addition, the stock needed to have at least 52 weeks of price history at the time of consideration. To calculate excess returns of constructed portfolios, the short-term Repo rate was used as a proxy for the risk-free rate. The Repo rate was preferred over longer term government bonds because a number of factors can impact the liquidity and pricing of government bonds. These factors may include government regulations, investor sentiment and foreign investment flows, among others. Repo rate data were collected from the South African Reserve Bank (SARB).

\section{Data processing}

In this study the relationship between ex-ante risk and total subsequent returns was assessed by evaluating the performance of equally weighted quintile portfolios. To construct these portfolios, the sample shares were sorted on two factor metrics, namely standard deviation (a measure of total risk) and beta (a measure of relative risk).

Standard deviation was calculated as the square root of the variance, where variance is a measure of spread, indicating the aggregate distance of each observation from the mean (Shapiro \& Wilk 1965). Standard deviation is a popular measure of dispersion used in financial analysis. The standard deviation on the share level was calculated by:

$\mathrm{SD}_{i}=\sqrt{\frac{1}{n} \sum_{t=1}^{n}\left(x_{i t}-\overline{x_{i}}\right)^{2}}$

where:

$\mathrm{SD}_{\mathrm{i}}=$ Standard deviation of stock $i$;

$n=$ number of observations in the look back period;

$x_{i t}=$ return observation of stock $i$ in week $t$;

$\bar{x}_{i}=$ stock i's arithmetic mean rate of return over the look back period.

The second factor metric employed was beta. Beta measures the volatility of an individual security by comparing its price movement to the market portfolio over time (Sharpe 1964). Beta thus measures relative (or systematic) risk. Beta was calculated by:

$\operatorname{Beta}_{i}=\frac{\operatorname{Cov}\left(r_{i} r_{m}\right)}{\operatorname{Var}\left(r_{m}\right)}$

where:

Beta $_{i}=$ Beta of the stock $i$;

$r_{i}=$ return of stock $i$

$r_{m}=$ return of the market portfolio;

$\operatorname{Cov}\left(r_{i} r_{m}\right)=$ the covariance between the returns of stock $i$ and the market portfolio;

$\operatorname{Var}\left(r_{m}\right)=$ the variance of the return of the market portfolio.

Each factor metric was constructed on a monthly basis using weekly price returns over a 52-week look back period. Shares with the highest observed risk measure were allocated to the high-risk quintile portfolio and the shares with the lowest observed risk measure were assigned to the low-risk quintile portfolio. The equally weighted quintile portfolios were rebalanced monthly, and, in line with similar studies, transaction costs were ignored throughout the analysis. Subsequently the total return for a one-month holding period was calculated and recorded for each quintile portfolio. The total return was calculated using adjusted prices that account for the impact of dividends, share splits and share buybacks. In addition to the five portfolios, an EBM portfolio was constructed using the same sample of shares as identified for the quintile portfolios.

\section{Data analysis}

For the primary objective of this study, the relative performance between the low-risk and high-risk quintile 
portfolios was assessed. The statistical significance of outperformance was assessed using paired $t$-tests.

For the secondary objective, the risk-adjusted performance of the low-risk quintile portfolio was assessed. Two riskadjusted measures were employed, namely the Sharpe ratio and the CAPM Jensen's alpha.

The formula for the Sharpe ratio is given as:

$S R_{i}=\frac{R_{i}-R f}{\sigma_{i}}$

[Eqn 4]

where:

$S R_{i}=$ Sharpe ratio of portfolio $i$;

$R_{i}=$ geometric annual return of quintile portfolio $i$;

$R_{f}=$ annualised risk-free rate of return;

$\sigma_{i}=$ annualised standard deviation of returns for quintile portfolio $i$.

Following Blitz and Van Vliet (2007), the statistical difference between two Sharpe ratios was calculated using the Jobson and Korkie (1981) test with the Memmel (2003) correction. This test statistic follows a normal distribution and is calculated using:

$$
Z=\frac{S R_{1}-S R_{2}}{\sqrt{\frac{1}{n}}\left[2\left(1-\rho_{1,2}\right)+\frac{1}{2}\left(S R_{1}^{2}+S R_{2}^{2}-S R_{1} S R_{2}\left(1+\rho_{1,2}^{2}\right)\right)\right]}
$$

where:

$S R_{1}=$ the Sharpe ratio of portfolio 1;

$S R_{2}=$ the Sharpe ratio of portfolio 2;

$\rho_{1,2}=$ the correlation between portfolios 1 and 2;

$n=$ the number of observations.

Lastly, the single-factor CAPM Jensen's alpha represents the average return of a portfolio over and above the expected return predicted by the CAPM (Jensen 1969). For this study the CAPM-adjusted alphas were estimated using the regression equation:

$R_{i t}-R_{f t}=\alpha_{i}+\beta_{i}\left(R_{m t}-R_{f t}\right)+\varepsilon_{i}$

[Eqn 6]

where:

$R_{i t}=$ return in month $t$ of quintile portfolio $i$;

$R_{m t}=$ return in month $t$ of on the market portfolio;
$R_{f t}=$ the risk-free rate in month $t$;

$\beta_{i}=$ estimated factor exposure of portfolio $i$;

$\alpha_{i}=$ CAPM-adjusted alpha of portfolio $i$.

Single factor CAPM-adjusted alphas were calculated relative to the equally weighted market portfolio as well as relative to the SWIX index.

\section{Results}

This section presents and discusses the empirical findings of the study in two parts. The first part examines the results using beta, and the second part uses standard deviation as the risk metric.

\section{Beta quintile portfolio analysis}

Table 1 contains a summary of the main results for the quintile portfolios ranked on past 52-week beta as a factor metric for risk. The relationship between ex-ante beta and subsequent return appears to be quite weak. Quintile portfolio 5 (P5) containing high beta shares and quintile portfolio 1 (P1) with low beta shares, both underperformed the EBM and the SWIX. P1 and P5 were also the worst performing among all portfolios analysed. The best performing quintile portfolio was $\mathrm{P} 4$ with $10.78 \%$ annualised excess return.

When looking at the ex-post standard deviations, there is generally a decreasing trend from high beta to low beta portfolios. The high-beta quintile portfolio (P5) had an annualised standard deviation of $18.18 \%$, roughly 1.5 times that of the EBM. The Sharpe ratios of the quintile portfolios were all lower than those of the EBM and SWIX. Both P1 and P5 had Sharpe ratios that were significantly lower than the Sharpe ratio of the EBM at the $1 \%$ level. There is, however, no clear observed pattern between the Sharpe ratios of the different quintile portfolios.

Table 2 shows the output from the two CAPM style regressions employing the beta sorted quintile portfolios as the dependent variable. For the first regression the SWIX and for the second regression the EBM were employed as the independent variable. This analysis shows that the low beta portfolio (P1) registered a 17 basis point alpha relative to the SWIX (statistically significant at the 10\% level). In contrast, the low-beta portfolio generated zero alpha relative to the EBM. For both regressions the betas decrease monotonically for the consecutive quintile portfolios. This finding supports

TABLE 1: Quintile portfolios based on historical beta.

\begin{tabular}{|c|c|c|c|c|c|c|c|}
\hline Variable & $\begin{array}{c}\text { P1 } \\
\text { (Low Beta) }\end{array}$ & P2 & P3 & P4 & $\begin{array}{c}\text { P5 } \\
\text { (High Beta) }\end{array}$ & EBM & SWIX \\
\hline Annualised return & $14.80 \%$ & $17.04 \%$ & $16.29 \%$ & $18.07 \%$ & $15.96 \%$ & $16.28 \%$ & $16.42 \%$ \\
\hline Annualised excess return $\left(R_{i}-R_{f}\right)$ & $7.51 \%$ & $9.75 \%$ & $9.00 \%$ & $10.78 \%$ & $8.67 \%$ & $8.98 \%$ & $9.13 \%$ \\
\hline Rank & 7 & 2 & 4 & 1 & 6 & 5 & 3 \\
\hline Annualised standard deviation & $12.55 \%$ & $13.41 \%$ & $13.30 \%$ & $15.58 \%$ & $18.18 \%$ & $12.05 \%$ & $14.14 \%$ \\
\hline Sharpe ratio & $0.60 * * *$ & 0.73 & $0.68 * *$ & 0.69 & $0.48 * * *$ & 0.75 & 0.65 \\
\hline ( $z$-value) & -3.05 & -0.54 & -2.04 & -1.33 & -5.37 & - & - \\
\hline
\end{tabular}

Note: Statistical significance of portfolio Sharpe ratios were tested relative to the EBM.

EBM, equally weighted benchmark; SWIX, Shareholder Weighted Index.

$* * *$, significant at the $1 \%$ level; **, significant at the $5 \%$ level. 
TABLE 2: Beta sorted quintile portfolio capital asset pricing model style regressions.

\begin{tabular}{|c|c|c|c|c|c|}
\hline Variable & $\begin{array}{c}\text { P1 } \\
\text { (Low Beta) }\end{array}$ & P2 & P3 & P4 & $\begin{array}{c}\text { P5 } \\
\text { (High Beta) }\end{array}$ \\
\hline \multicolumn{6}{|c|}{ SWIX as independent variable } \\
\hline Beta & 0.60 & 0.69 & 0.75 & 0.94 & 1.13 \\
\hline Monthly alpha (\%) & $0.17^{*}$ & $0.27 * *$ & $0.17^{*}$ & 0.19 & -0.07 \\
\hline ( $t$-value) & 1.89 & 2.11 & 1.70 & 1.15 & -0.72 \\
\hline \multicolumn{6}{|c|}{ EBM as independent variable } \\
\hline Beta & 0.86 & 1.01 & 1.01 & 1.13 & 1.24 \\
\hline Monthly alpha (\%) & 0.00 & 0.06 & 0.01 & 0.07 & -0.12 \\
\hline ( $t$-value) & 0.49 & 0.43 & 0.01 & -0.04 & -1.05 \\
\hline
\end{tabular}

Notes: The following regression equation was conducted for the CAPM Jensen's alph measure: $R-R=\alpha+\beta(R-R)+\varepsilon$, where $R$ is the return on each quintile portfolio. EBM, equally weighted benchmark; SWIX, Shareholder Weighted Index.

**, significant at the $5 \%$ level; *, significant at the $10 \%$ level.

the argument of beta persistence, where shares with high $e x-$ post betas exhibit high ex-ante betas (see Andersen et al. 2006). The high-beta quintile exhibits negative monthly alpha to both EBM and SWIX portfolios; however, neither was significantly different from zero.

A graphic illustration of the results of the beta sorted quintile portfolios is given in Figures 1 and 2. The theoretical relation suggests that an investor should expect similar levels of riskadjusted returns across all quintile portfolios. In other words, investors should expect higher (lower) levels of excess returns when exposed to higher (lower) levels of risk. Thus, all quintile portfolios should theoretically plot on the theoretical CML. In Figure 1, the volatility-return relations of beta sorted portfolios are indicated along with the CML, which indicates the theoretical relation between volatility and return. Apart from the underperformance of high beta shares, there appears to be no clear relationship between historical beta and subsequent risk-adjusted performance. This result differs from previous studies where a negative relationship was found between beta and subsequent returns (see Strugnell et al. 2011; Van Rensburg \& Robertson 2003).

In Figure 2, the beta-return relation of beta sorted portfolios is indicated along with the security market line (SML), which indicates the theoretical relation between beta and return (Sharpe 1964). In line with the results in Figure 1, the highvolatility portfolio (P5) underperforms and there appears to be no clear relationship between historical beta and subsequent risk-adjusted performance.

\section{Standard deviation quintile portfolio analysis}

Table 3 contains a summary of the main results for the quintile portfolios ranked on the past 52 week standard deviation as a factor metric for risk. The relation between ex-ante risk and subsequent returns seems to come out more strongly than from the beta quintile portfolio analysis. High-volatility quintile portfolios had lower annualised returns, higher observed standard deviations and lower Sharpe ratios than the lower volatility portfolios. There was a general decline in average return from the low-volatility portfolios through to high-volatility portfolios. The lowest volatility portfolio (P1) generated an annualised return in excess of the risk-free rate of $12.93 \%$, which was higher than the excess return associated

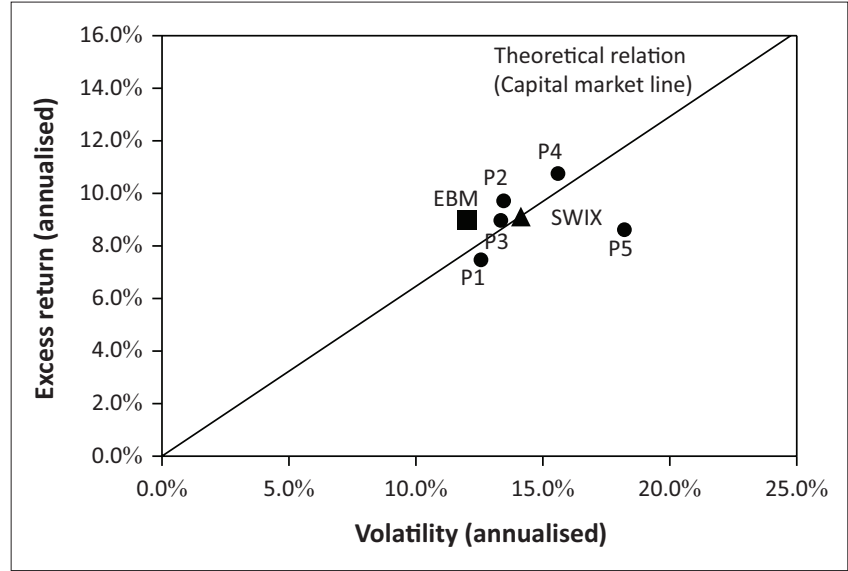

FIGURE 1: Beta sorted portfolios and the capital market line.

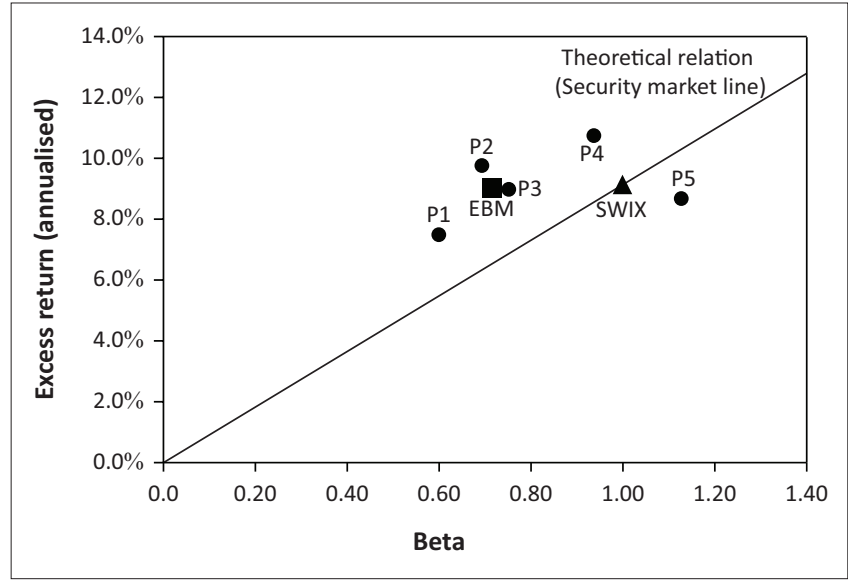

FIGURE 2: Beta sorted portfolios and the security market line.

with the EBM (8.98\%) and the SWIX (9.13\%). The difference in annualised return between the top and bottom quintile portfolio was 7.64\%. Ex-post standard deviations can be seen to decrease monotonically for the consecutive quintile portfolios. The volatility of the lowest volatility quintile portfolio (P1) of $11.74 \%$ is similar to the observed volatility of the EBM (12.05\%), but much lower than that of the highvolatility quintile portfolio (P5) which is $20.47 \%$.

A similar pattern is observed when looking at the Sharpe ratios of the quintile portfolios. The high-volatility portfolio (P5) produced the lowest Sharpe ratio (0.26). The highest Sharpe ratio (1.1) observed came from the low-volatility portfolio (P1). Compared with the Sharpe ratio of the EBM (0.75), the Sharpe ratios of both P1 and P5 were significantly different at the $1 \%$ level of significance.

Table 4 shows the output from the two CAPM style regressions employing the standard deviation sorted quintile portfolios as the dependent variable. For the first regression the SWIX and for the second regression the EBM were employed as the independent variable in the regression. The analysis indicates that relative to the SWIX, the low-volatility portfolio (P1) combines a beta of 0.58 with a positive monthly alpha of $0.57 \%$. This alpha is significantly different from zero at the $1 \%$ significance level. The observed betas decrease 
TABLE 3: Quintile portfolios based on historical standard deviation

\begin{tabular}{|c|c|c|c|c|c|c|c|}
\hline Variable & $\begin{array}{c}\text { P1 } \\
\text { (Low SD) }\end{array}$ & $\mathbf{P 2}$ & P3 & P4 & $\begin{array}{c}\text { P5 } \\
\text { (High SD) }\end{array}$ & EBM & SWIX \\
\hline Annualised return & $20.22 \%$ & $17.52 \%$ & $17.65 \%$ & $13.60 \%$ & $12.58 \%$ & $16.28 \%$ & $16.42 \%$ \\
\hline Annualised excess return $\left(R_{i}-R_{f}\right)$ & $12.93 \%$ & $10.23 \%$ & $10.36 \%$ & $6.31 \%$ & $5.29 \%$ & $8.98 \%$ & $9.13 \%$ \\
\hline Rank & 1 & 3 & 2 & 6 & 7 & 5 & 4 \\
\hline Annualised standard deviation & $11.74 \%$ & $13.56 \%$ & $14.01 \%$ & $15.39 \%$ & $20.47 \%$ & $12.05 \%$ & $14.14 \%$ \\
\hline Sharpe ratio & $1.10 * * *$ & 0.75 & 0.74 & $0.41 * * *$ & $0.26 * * *$ & 0.75 & 0.65 \\
\hline (z-value) & 6.67 & 0.21 & -0.17 & -8.63 & -7.83 & - & - \\
\hline
\end{tabular}

EBM, equally weighted benchmark; SWIX, Shareholder Weighted Index

***, significant at the $1 \%$ level.

TABLE 4: Standard deviation sorted quintile portfolio capital asset pricing model style regressions.

\begin{tabular}{|c|c|c|c|c|c|}
\hline Variable & $\begin{array}{c}\text { P1 } \\
\text { (Low SD) }\end{array}$ & P2 & P3 & P4 & $\begin{array}{c}\text { P5 } \\
\text { (High SD) }\end{array}$ \\
\hline \multicolumn{6}{|c|}{ SWIX as independent variable } \\
\hline Beta & 0.58 & 0.72 & 0.80 & 0.91 & 1.11 \\
\hline Monthly alpha & $0.57 \% * * *$ & $0.29 \%$ & $0.24 \%$ & $-0.12 \%$ & $-0.27 \%$ \\
\hline ( $t$-value) & 2.97 & 1.41 & 1.28 & -0.62 & -0.91 \\
\hline \multicolumn{6}{|c|}{ EBM as independent variable } \\
\hline Beta & 0.80 & 0.99 & 1.04 & 1.16 & 1.26 \\
\hline Monthly alpha & $0.42 \% * * *$ & $0.11 \%$ & $0.09 \%$ & $-0.27 \% *$ & $-0.35 \%$ \\
\hline$(t$-value) & 2.80 & 0.77 & 0.64 & -1.86 & -1.11 \\
\hline
\end{tabular}

Notes: For the CAPM Jensen's alpha measure, we applied the regression equation $R_{i t}-R_{f t}=$ $\alpha_{i}+\beta_{i}\left(R_{m t}-R_{f t)}+\varepsilon_{i}\right.$, where $R_{i t}$ is the return on each quintile portfolio.

EBM, equally weighted benchmark; SWIX, Shareholder Weighted Index.

***, significant at the $1 \%$ level; $*$, significant at the $10 \%$ level.

monotonically when moving from high-volatility to lowvolatility quintile portfolios, suggesting that volatility and beta are related risk measures. The high-volatility quintile portfolio (P5) produced negative monthly alphas relative to the SWIX $(-0.27 \%)$ and the EBM $(-0.35 \%)$. Contrary to the theoretical expectation, the results suggest a negative relation between risk and return. However, the result is in line with previous findings (see Khuzwayo 2015; Oladele \& Bradfield 2016; Panulo 2014).

The graphic illustration of these results can be seen in Figures 3 and 4 . The risk-return characteristics of volatility sorted portfolios can be seen to be in clear violation of the theoretical relationship suggested by the CML (Figure 3) and the SML (CAPM) in Figure 4. The low-volatility quintile portfolio (P1) produced risk-adjusted performance in excess of what both the CML and the SML would suggest. From Figure 3, it can be seen that high-volatility (low-volatility) shares have lower (higher) Sharpe ratios than the SWIX, and from Figure 4 it can be observed that high-volatility (lowvolatility) shares produce negative (positive) CAPM-adjusted alphas.

\section{Reconciliation of the research objectives}

This section includes a reconciliation of both the primary and secondary research objectives.

\section{Primary research objective}

As indicated earlier, the primary objective of this study was to determine whether low-risk portfolios outperform highrisk portfolios over the sample period. As can be seen in

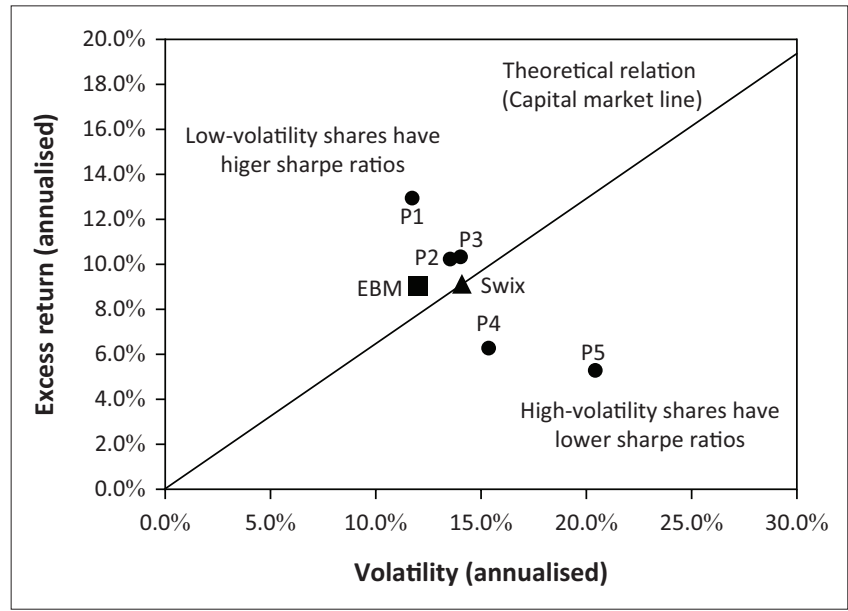

FIGURE 3: Volatility sorted portfolios and the capital market line.

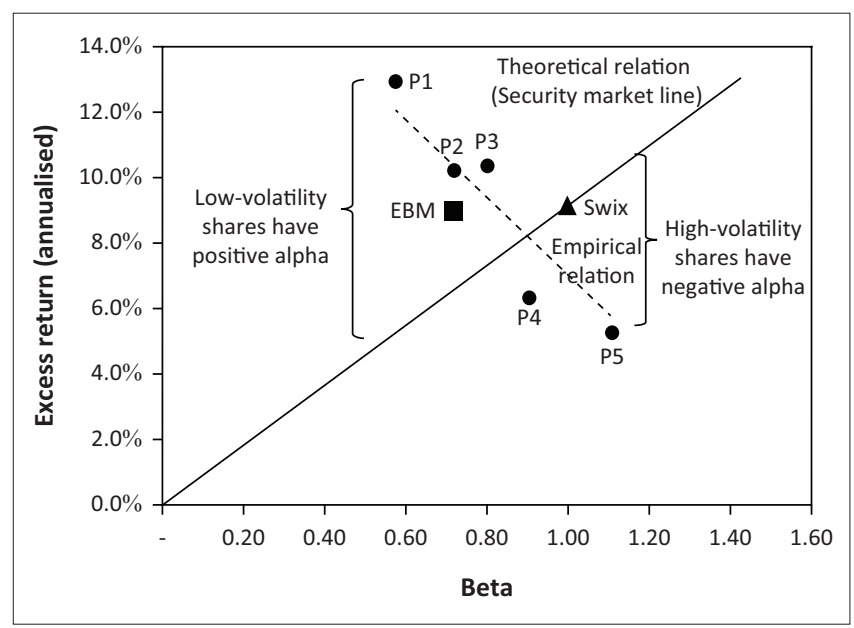

FIGURE 4: Volatility sorted portfolios and the security market line.

Table 5, inconsistent results were observed. Based on beta as a factor metric for risk, it was found that the low-beta quintile portfolio (P1) underperformed relative to the high-beta quintile portfolio (P5). On the basis of standard deviation as a factor metric for risk, the low-volatility quintile portfolio (P1) outperformed the high-volatility quintile portfolio (P5).

Hypothesis $1\left(\mathrm{H}_{1}\right)$ tested whether the low-risk quintile portfolio (P1) outperformed the high-risk quintile portfolio (P5) on a statistically significant basis. When using beta as a factor metric, there was no evidence that low-risk shares produce outperformance. However, when addressing the primary objective with standard deviation sorted quintile portfolios, the low-volatility quintile outperformed the 
high-volatility portfolio. This outperformance, however, was not statistically significant. Therefore, the first null hypothesis $\left(\mathrm{H}_{01}\right)$ could not be rejected on both accounts.

\section{Secondary research objective}

The secondary objective analysed the risk-adjusted performance of the low-risk quintile portfolio (based on standard deviation and beta) relative to the EBM. The hypothesis in this regard $\left(\mathrm{H}_{2}\right)$ tested whether the low-risk portfolio outperformed the EBM on a risk-adjusted basis. To address this hypothesis, two risk-adjusted performance measures (the Sharpe ratio and the CAPM-adjusted alpha) were employed.

Table 6 displays the risk-adjusted performance of the lowbeta quintile portfolio relative to the EBM. The Sharpe ratio of the low-beta quintile portfolio is significantly lower than that of the EBM. Similarly the low-beta quintile portfolio produced a CAPM-adjusted alpha of $0.00 \%$. Therefore, when using beta as the factor metric for risk, the second null hypothesis $\left(\mathrm{H}_{02}\right)$ could not be rejected. Thus, it cannot be concluded that the low-beta quintile portfolio produced significant outperformance.

The results, however, differ when using standard deviation as the factor metric for risk. As can be seen in Table 7, the lowvolatility quintile portfolio produced a higher Sharpe ratio and a positive CAPM-adjusted alpha (both significant at the $1 \%$ level). Therefore, based on standard deviation as a factor

TABLE 5: $t$-test output for beta and volatility sorted quintile portfolios.

\begin{tabular}{lcccc}
\hline Variable & $\begin{array}{c}\text { P1 } \\
\text { (Low Beta) }\end{array}$ & $\begin{array}{c}\text { P5 } \\
\text { (High Beta) }\end{array}$ & $\begin{array}{c}\text { P1 } \\
\text { (Low SD) }\end{array}$ & $\begin{array}{c}\text { P5 } \\
\text { (High SD) }\end{array}$ \\
\hline Mean monthly rate of return & $1.22 \%$ & $1.38 \%$ & $1.60 \%$ & $1.17 \%$ \\
Variance & 0.0013 & 0.0028 & 0.0011 & 0.0035 \\
Observations & 170 & 170 & 170 & 170 \\
$(t$-value) & -0.455 & - & 1.058 & - \\
$(p$-value) one-tailed test & 0.33 & - & 0.15 & - \\
\hline
\end{tabular}

TABLE 6: Risk-adjusted performance of the low-beta quintile portfolio.

\begin{tabular}{lcc}
\hline Variable & $\begin{array}{c}\text { P1 } \\
\text { (Low Beta) }\end{array}$ & EBM \\
\hline Sharpe ratio & 0.60 & 0.75 \\
$(z$-value) & -3.05 & - \\
$(p$-value) & 0.00 & - \\
CAPM alpha versus EBM & $0.00 \%$ & - \\
$(t$-value) & 0.49 & - \\
$(p$-value) & 0.63 & - \\
\hline
\end{tabular}

CAPM, capital asset pricing model; EBM, equally weighted benchmark.

TABLE 7: Risk-adjusted performance of the low-volatility quintile portfolio.

\begin{tabular}{lcc}
\hline Variable & $\begin{array}{c}\text { P1 } \\
\text { (Low SD) }\end{array}$ & EBM \\
\hline Sharpe ratio & $1.10^{* * *}$ & 0.75 \\
$(z$-value) & 6.67 & - \\
( $p$-value) & 0.00 & - \\
CAPM alpha versus EBM & $0.42 \% * * *$ & - \\
$(t$-value) & 2.80 & - \\
$(p$-value) & 0.01 & - \\
\hline
\end{tabular}

CAPM, capital asset pricing model; EBM, equally weighted benchmark.

$* * *$, significant at the $1 \%$ level. metric for risk, the second null hypothesis $\left(\mathrm{H}_{02}\right)$ could be rejected in favour of the alternative hypothesis. This finding is similar to that of Blitz and Van Vliet (2007), where evidence was found that a global low-volatility decile portfolio produced a statistically significantly higher Sharpe ratio than the market portfolio on a $5 \%$ level.

\section{Discussion and conclusions}

The primary objective of this study was to assess whether shares with lower historical risk metrics produced higher risk-adjusted returns in the South African equity market. The study was undertaken to contribute to the existing body of knowledge on the topic, specifically within the South African context. The study expands on the work of Van Rensburg and Robertson (2003) and Strugnell et al. (2011) by employing not only beta, but also standard deviation (volatility) as an additional measure of risk. This study has shown that shares with low historical volatility exhibit greater risk-adjusted returns, both in terms of higher Sharpe ratios and better CAPM-adjusted alphas. Shares with higher ex-ante volatility produced lower average returns, higher ex-post volatility, higher ex-post betas and smaller Sharpe ratios. These results are in line with Blitz and Van Vliet (2007), who considered a sample of global shares. The results in this study are also consistent with those of Ang et al. (2006), who found large negative alphas for US shares with high idiosyncratic volatility. The results could also explain the outperformance of the various low-volatility trading strategies investigated by Khuzwayo (2015), Panulo (2014) and Oladele and Bradfield (2016).

The relationship between ex-ante beta and subsequent returns was less clear. Contrary to the findings of Van Rensburg and Robertson (2003) and Strugnell et al. (2011), no evidence was found of lower ex-ante betas leading to higher ex-post returns. As total risk (volatility) consists of two components systematic risk (beta) and idiosyncratic risk - it could be that idiosyncratic risk is driving the low-risk anomaly observed in the market for the July 2004-September 2018 period.

Possible explanations for the observed low-volatility anomaly include behavioural biases among investors. Potential behavioural biases could include representative bias, where investors prefer shares where news-flow tends to be higher (thus more volatile), as opposed to low-news low-risk shares. Other suggestions for this observed anomaly include the limits to arbitrage emanating from the benchmark cognisant mandate of the typical institutional investor (Baker et al. 2011). Investors appear to underestimate the persistence of historical volatility, and overestimate expected return for high-volatility shares. If lower expectations were reflected in high-volatility stock prices, the risk return relationship would be positive as opposed to the observed negative relation. Linked to this explanation is the possibility that benchmark cognisant investors believe they can add incremental outperformance to their portfolios by including shares with higher observed volatility. The aggregate effect of this is that the prices of high-volatility shares are elevated 
relative to low-volatility shares. The risk-adjusted ex-ante total returns of low-volatility shares therefore could end up being higher than expected.

Another possible explanation for the observed low-volatility effect is the possible impact of small size and low liquidity effects. Although an attempt was made to mitigate this impact by limiting the study to the largest 120 share in the SWIX, it is possible that these effects were still not fully controlled for. This study did not specifically control for potential sector bias within volatility sorted portfolios, so it is possible that some of the observed low-volatility effect could be explained by sector concentration as suggested by Khuzwayo (2015). However, even after controlling for sector bias in the low-volatility trading strategies investigated, Oladele and Bradfield (2016) found that these strategies outperformed.

This study did not consider the potential impact of trading costs. If constructed portfolios realised high turnover, the net return realised after taking into account transaction costs could be negatively impacted. This could potentially change the results observed. Although it was beyond the scope of this study, future studies could potentially incorporate transaction costs into the analysis.

A notable observation of the study was that high beta shares provided negative alpha relative to the SWIX and the EBM. Although these were not statistically significant, this suggests that, contrary to the CAPM, systematic risk is not priced by the market. This finding might be attributed to investors in aggregate overweighting high beta shares in an attempt to enhance returns. The prices of high beta shares rise and the expected CAPM high beta effect is traded away.

\section{Managerial implications}

This study provides a better understanding of the relationship between risk and return in the South African listed equity market. Contrary to the theoretical framework of the SML, the empirical evidence stood in contrast to theoretical expectations. The negative relationship found between volatility and return has important managerial implications. Unless investors take this implication into account, their misplaced expectation of being rewarded for assuming more risk could influence their investment performance negatively.

The assumption that return in an investment portfolio could be enhanced by taking on more risk could be wrong. In fact, it seems that fund managers could potentially enhance returns and decrease risk in their portfolios by focussing on shares with low historical volatility. There is, however, little motivation to include historical beta as a consideration in the stock selection process. Furthermore, the evidence presented casts some doubt on the appropriateness of relying on the CAPM framework to estimate cost of equity in South Africa.

Lastly, the analysis of risk-adjusted performance of lowvolatility strategies could be of value to individual and institutional investors who are interested in high Sharpe ratio investments. These investors could increase their allocation to low-volatility shares. Moreover, within a strategic asset allocation framework, it could be of value to distinguish between low-risk and high-risk shares within the traditional equity asset class.

\section{Acknowledgements}

The authors extend their gratitude to Ms Marnia Wessels for her research assistance, Prof. Johan de Villiers and Prof. Suzette Viviers for their constructive comments.

\section{Competing interests}

The authors declare that they have no financial or personal relationships that may have inappropriately influenced them in writing this paper.

\section{Authors' contributions}

J.P.S. and L.T. both have made a substantial contribution to the article, both have revised the content of the manuscript and both have approved the submitted version.

\section{Ethical considerations}

Ethical clearance was obtained from the research ethics committee: Humanities, Project Number: ONB-2018-6919.

\section{Funding}

This research received no specific grant from any funding agency in the public, commercial or not-for-profit sectors.

\section{Data availability statement}

Data sharing is not applicable to this article as no new data were created or analysed in this study.

\section{Disclaimer}

The views expressed in the submitted article are those of the authors and not an official position of the institution.

\section{References}

Andersen, T.G., Bollerslev, T., Diebold, F.X. \& Wu, G., 2006, 'Realized beta: Persistence and predictability', in T. Fomby \& D. Terrell (eds.), Econometric analysis of financial and economic time series (Advances in econometrics, Volume 20 Part 2), pp. 1-39, Emerald Group Publishing Limited, Bingley.

Ang, A., Hodrick, R.J., Xing, Y. \& Zhang, X., 2006, 'The cross-section of volatility and expected returns', The Journal of Finance 61(1), 259-299. https://doi. org/10.1111/j.1540-6261.2006.00836.x

Baker, N.L. \& Haugen, R.A., 2012, 'Low risk stocks outperform within all observable markets of the world', viewed 10 January 2018, from http://lowvolatilitystocks. com/wp-content/uploads/Low_Risk_Stocks_Outperform.pdf.

Baker, M., Bradley, B. \& Wurgler, J., 2011, 'Benchmarks as limits to arbitrage: Understanding the low-volatility anomaly', Financial Analysts Journal 67(1), 40-54. https://doi.org/10.2469/faj.v67.n1.4

Bali, T.G., Cakici, N., Yan, X. \& Zhang, Z., 2005, 'Does idiosyncratic risk really matter?', The Journal of Finance 60(2), 905-929. https://doi.org/10.1111/j.1540-6261. 2005.00750.x

Black, F., Jensen, M.C. \& Scholes, M.S., 1972, 'The capital asset pricing model: Some empirical tests', in M.C. Jensen (ed.), Studies in the theory of capital markets, pp. 79-121, Praeger, New York. 
Blitz, D., Pang, J. \& Van Vliet, P., 2013, 'The volatility effect in emerging markets', Emerging Markets Review 16, 31-45. https://doi.org/10.1016/j.ememar.2013.02.004

Blitz, D. \& Van Vliet, P., 2007, 'The volatility effect: Lower risk without lower return' Journal of Portfolio Management 2007(Fall), 102-113.

Campbell, J.Y., Lettau, M., Malkiel, B.G. \& Xu, Y., 2001, 'Have individual stocks become more volatile? An Empirical Exploration of Idiosyncratic Risk', The Journal of Finance 56(1), 1-43. https://doi.org/10.1111/0022-1082.00318

Clarke, R., De Silva, H. \& Thorley, S., 2011, 'Minimum-variance portfolio composition', Journal of Portfolio Management 37(2), 31-45. https://doi.org/10.3905/ jpm.2011.37.2.031

Fama, E.F. \& French, K.R., 1993, 'Common risk factors in the returns on stocks and bonds', Journal of Financial Economics 33(1), 3-56. https://doi.org/10.1016/0304405X(93)90023-5

Goyal, A. \& Santa-Clara, P., 2003, 'Idiosyncratic risk matters!', The Journal of Finance 58(3), 975-1007. https://doi.org/10.1111/1540-6261.00555

Haugen, R.A. \& Heins, A.J., 1975, 'Risk and the rate of return on financial assets: Some old wine in new bottles', Journal of Financial and Quantitative Analysis 10(5), 775-784. https://doi.org/10.2307/2330270

Jensen, M.C., 1969, 'Risk, the pricing of capital assets, and the evaluation of investment portfolios,' Journal of Business 42, 167-247.

Jobson, J.D. \& Korkie, B.M., 1981, 'Performance hypothesis testing with the Sharpe and Treynor measures', Journal of Finance 36(4), 889-908.

Johannesburg Stock Exchange, 2014, FTSE-JSE Shareholder weighted indices brochure viewed 10 January 2018, from https://www.jse.co.za/services/market-data/ indices/ftse-jse-africa-index-series/shareholder-weighted.

Khuzwayo, B., 2015, 'Understanding the low volatility anomaly in the South African equity market', Mcom thesis, Dept. Operations Research, University of Cape Town.

Levy, H., 1978, 'Equilibrium in an imperfect market: A constraint on the number of securities in the portfolio', The American Economic Review 68(4), 643-658.

Lintner, J., 1965, 'Security prices, risk and maximal gains from diversification', Journa of Finance 20(6), 587-615. https://doi.org/10.1111/j.1540-6261.1965.tb02930.x

Ludvigson, S.C. \& Ng, S., 2005, 'The empirical risk-return relation: A factor analysis approach', Journal of Financial Economics 83(1), 171-222. https://doi.org/ 10.1016/j.jfineco.2005.12.002
Markowitz, H., 1952, 'Portfolio selection', The Journal of Finance 7(1), 77-91. https:// doi.org/10.1111/j.1540-6261.1952.tb01525.x

Memmel, C., 2003, 'Performance hypothesis testing with the Sharpe ratio', Finance Letters 1(1), 21-23.

Merton, R.C., 1987, 'A simple model of capital market equilibrium with incomplete information', The Journal of Finance 42(3), 483-510. https://doi.org/10.1111/ j.1540-6261.1987.tb04565.x

Mossin, J., 1966, 'Equilibrium in a capital asset market', Econometrica 34(4), 768-783. https://doi.org/10.2307/1910098

Miller, M.H. \& Scholes, M., 1972, 'Rates of return in relation to risk: A reexamination of some recent findings', in M.C. Jensen (ed.), Studies in the theory of capital markets, pp. 47-78, Praeger Publishers, New York.

Oladele, O.S. \& Bradfield, D., 2016, 'Low volatility sector-based portfolios: A South African case', Orion 32(1), 55-78. https://doi.org/10.5784/32-1-541

Panulo, B., 2014, 'Risk parity and other risk based portfolio allocation approaches in South African and international equity markets', Mcom thesis, Dept. Investment Management, University of Cape Town.

Shapiro, S.S \& Wilk, M.B., 1965, 'An analysis of variance test for normality (complete samples)', Biometrica 52(3/4), 591-611. https://doi.org/10.1093/biomet/52. 3-4.591

Sharpe, W.F., 1964, 'Capital asset prices: A theory of market equilibrium under conditions of risk', The Journal of Finance 19(3), 425-442. https://doi.org/ 10.1111/j.1540-6261.1964.tb02865.x

Strugnell, D., Gilbert, E. \& Kruger, R., 2011, 'Beta, size and value effects on the JSE, 1994-2007', Investment Analysts Journal 40(74), 1-17. https://doi.org/10.1080/ 10293523.2011.11082537

Treynor, J.L., 1961, 'Market value, time, and risk', Unpublished manuscript, "Rough Draft" dated 8/8/61, 95-209.

Treynor, J.L., 1962, 'Toward a theory of market value of risky assets', Unpublished manuscript, "Rough Draft" dated by Mr. Treynor to the fall of 1962. A final version was published in R.A. Korajczyk (ed), 1999, Asset Pricing and Portfolio Performance, pp. 15-22, Risk Books, London.

Van Rensburg, P. \& Robertson, M., 2003, 'Size, price-to-earnings and beta on the JSE Securities Exchange', Investment Analysts Journal 32(58), 7-16. https://doi.org/ 10.1080/10293523.2003.11082449 